\title{
Digital Twinning for Smart Industry
}

\author{
Sławomir Luściński ${ }^{1}$ \\ \{slawomir.luscinski@tu.kielce.pl\} \\ Kielce University of Technology, al. Tysiąclecia Państwa Polskiego 7, \\ 25-314 Kielce, Poland
}

\begin{abstract}
The Smart Industry is driven by the intensive use of information and communication technologies in the automation of manufacturing, supply chain management and new product development. This paper aims to present insights and enterprise perspective view on Digital Twins emerging technology which is considered as one of the most critical in the digital transformation of the industry. The concept of Digital Twin Shop-floor is used to investigate to which extent existing IT technologies can be used to prototyping and develop Digital Twins systems.
\end{abstract}

Keywords: Industry 4.0, Smart industry, Digital Twin, FlexSim.

\section{Introduction}

Term Industry 4.0 (I4.0) coined in German High-Tech-Strategy 2020 action plan presented at the Hannover-Messe Fairs 2011 [1] become one of the most recognisable terms for identifying an ongoing wave of automation driven by applying advanced information and communication technologies (ICT) which are increasingly prevalent in industrial automation. According to the definition of the Plattform i40.de, term Industry 4.0 "refers to the intelligent networking of machines and processes for the industry with the help of information and communication technology" (Plattform-i40.de). In the international context, not limited to Germany industry strategy development perspective, there are terms with similar concepts connotations like Smart Factory, Digital Transformation, Internet of Things, Industrial Internet, Internet of everything, manufacturing based on Cyber-Physical System, Made in China 2025 [2] which are developed in different countries for at least two decades, starting from the USA. To cover all of those initiatives it was assumed to use Smart Industry term which seems to be the most capacious term for naming whole of phenomena occurring in the modern industry both in engineering and in economics.

The Smart Industry is driven by the intensive use of information and communication technologies (ICT) in designing and managing both production systems and smart products. Technologies like the Internet of Things (IoT), Cyber-Physical Systems (CPS), Augmented Reality, Big Data and others are developed and implemented to achieve a high degree of flexibility in production systems.

The IoT is the network of physical objects with embedded systems (sensors, actuators) which can interconnect through the Internet Protocol (IP). IoT enables interaction with physical objects due to the implementation of hardware and software communication interfaces including internet connectivity [3]. 
Cyber-Physical System is a mechanism controlled or monitored by computer algorithms; CPS integrates computational (cyber) world and physical world. Physical processes are a source of data for computational processes that generate control signals appropriate to the results of calculations [4]. Networked CPS create distributed, intelligent systems with the ability to be formed into a smart grid of production assets for flexible manufacturing purposes. The Cyber-physical systems produce enormous volumes of data stored in electronic format, enabling analysis for prediction and planning. Fig. 1 presents extended the stage model of Manufacturing planning and control (MPC) systems evolution (adapted from [5]).

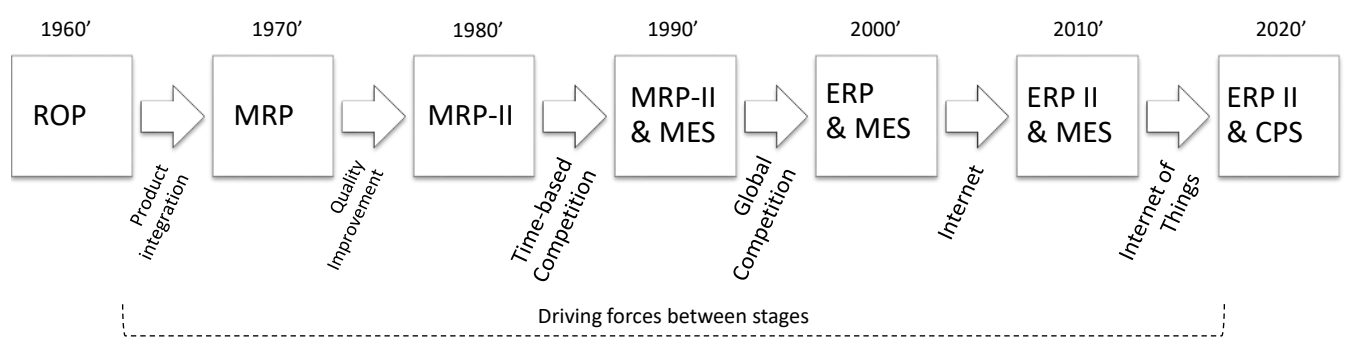

Fig. 1. Manufacturing Planning and Control stage model [6].

Manufacturing (or production) planning and control have evolved through seven major stages due to forces driving the evolutionary process between stages [6]:

1) reorder point $(\mathrm{ROP})$ systems,

2) materials requirement planning (MRP) systems; due to production integration,

3) manufacturing resource planning (MRP-II) systems; due to quality improvement,

4) MRP-II with manufacturing execution systems (MES); due to time-based competition,

5) Enterprise resource planning systems (ERP) with MES; due to global competition.

6) Extended ERP (ERP II) with MES - transition driving force: internet,

7) extended ERP (ERP II) with autonomy and self-control through CPS intelligence (elimination of MES) - transition driving force: internet of things and services.

Real-time data from CPS can be used to drive mirrored-in-software physical objects called digital twin to analyse and simulate real-world environment and events [7]. One of the Gartner's top strategic technology trends for 2017 is Digital Twinning [8]. It is predicted, that by 2021 , half of the large industrial companies will use this technology gaining a $10 \%$ improvement in effectiveness [9].

\section{Digital Twins}

\subsection{The concept of digital twins}

The idea of digital representation of physical objects for manipulation and simulation is present since the 1970s when electronics chips circuits design was supported with CAD systems developed as propriety software of major manufacturing companies. In the 1980s, along with personal computers expansion, computer-aided engineering tools were independently developed in order to interactive design and simulation of integrated circuits and printed board circuits (PCB). This class of tools since the mid-1980s is called EDA - 
Electronic Design Automation [10]. A similar process of evolving software tools from CAD through CAE to CAM took place in mechanical engineering.

The concept of digital twins of physical assets was coined in 2003 (or even 2002) at the University of Michigan for the formation of the Product Lifecycle Management (PLM) centre and consist of three parts [11]:

1) physical product in real space,

2) virtual product in a virtual space,

3) the connection of data and information that ties the two spaces together.

A widely recognised definition of the digital twin is as follows (Glaessegen and Stargel, 2012): "it is a is an integrated multi-physics, multi-scale, probabilistic simulation of a complex product and uses the best available physical models, sensor updates to mirror the life of its corresponding twin" [2]. According to Gartner, digital twins combined with the digital representation of facilities, people, processes will create new possibilities for more detailed simulation and analysis as well as for better control [8].

The phenomenon of growing digital resources was named in McKinsey report [12] as a Big Data which "refers to datasets whose size is beyond the ability of typical database software tools to capture, store, manage, and analyse". Big Data analysis become more and more vital for new product and service customer-oriented development, implementation of predictive maintenance, lean production. The future of Product Lifecycle Management (PLM) is based on the combination of Digital Twins and Big Data; it may be used in product design, manufacturing and service [2].

Smart manufacturing requires more interconnection and interoperability between virtual space and physical space of shop-floor leading finally to some convergence through a fourstage evolutionary process (Fig.2).

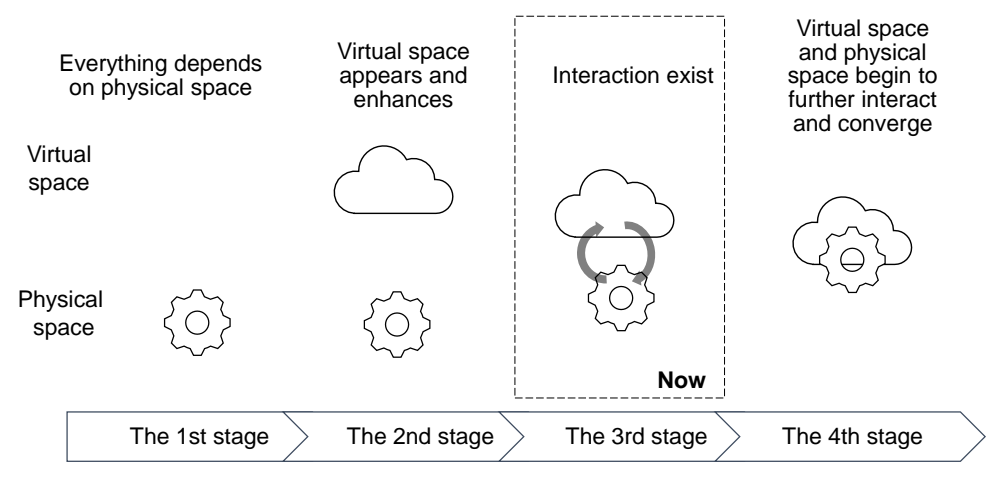

Fig. 2. The evolution process of shop-floor. Adapted from [11].

At the first stage, there were no information systems involved in shop-floor processes. At the second stage, we had a manufacturing and planning systems from 1st to 6th stage of MPC systems evolution stages (Fig.1). The transition from 2 nd stage to 3rd stage evolution of shop-floor was driven by computer integrated manufacturing (CIM) systems due to introduce in the 2000s digitalisation of machine tools (CNC) and product development (CAD/CAE/CAM). At the 3rd stage, that we are in now, we can observe increasing interaction between virtual and physical spaces through emerging IoT solutions and Big Data analysis. The 4th stage is based on intensive two-way interaction based on growing possibilities both 
cyber-physical systems and information systems (stage 7th of MPS). The digital twin is driving force for this stage.

\subsection{The concept of Digital Twin Shop-floor}

The concept of Digital Twin Shop-floor (DTS) is developed for the last two years in China [11]. Digital twin is used to provide an effective way of achieving the physical-virtual convergence for the shop-floor (4th stage in Fig. 2).

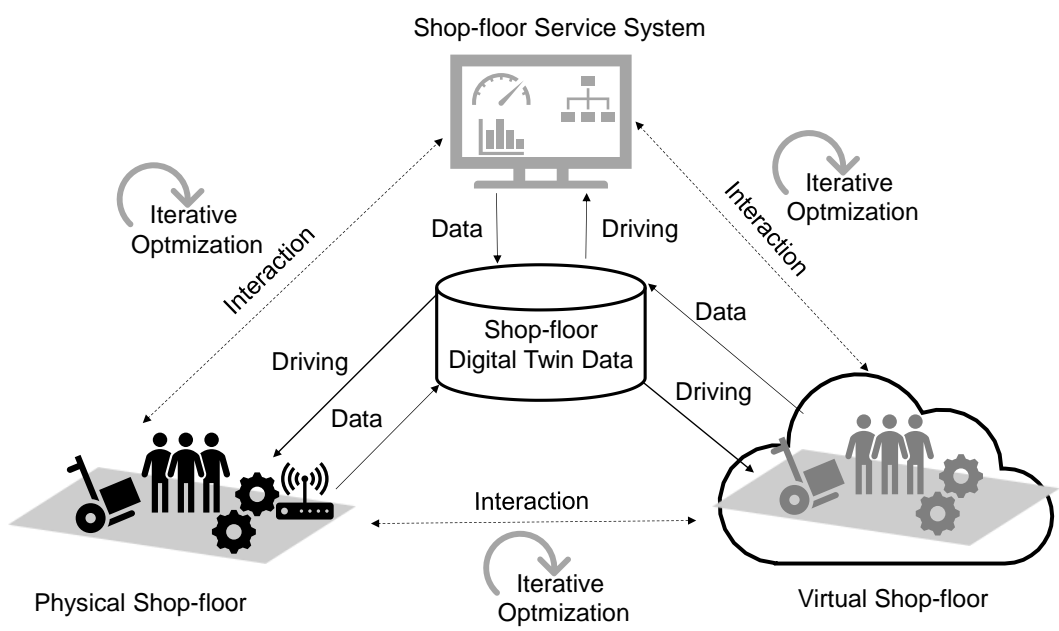

Fig. 3. A conceptual model of DTS. Adapted from [11].

The Digital Twin Shop-floor consist of four components [11], [2], [13]:

1) Physical Shop-floor (PS) - organised physical assets and materials;

2) Virtual Shop-floor (VS) - a multidimensional digital model of PS. VS evolves with PS, providing control orders for PS and optimising strategies for SSS;

3) Shop-floor Service System (SSS) - Enterprise Information system (EIS), configured to meet the specific demands of PS and VS;

4) Shop-floor Digital Twin Data (SDTD) - collects and stores data, aggregated data, fused data, algorithms, procedures, documentation of the product.

While PS, VS and SSS are evolving with time, continuous interactions based on dynamic and real-time associations mapping, and data/information/knowledge exchange, make them consistent with each other and can be optimised iteratively.

In presented concept SDTD plays a central role in the integration of data flows through Digital Twin Shop-floor in a heterogeneous environment of communications and data format standards. STDT should be based upon established canonical data model - common, enterprise-standard data structure. It makes SDTD the central repository of current and historical data in the company which is a vital resource, especially for Big Data analysis. Thus, the STDT may be used for enterprise-wide purposes, not limited to shop-floor management. 


\subsection{Digital twin business values}

The digital transformation based on the digital twining gives new opportunities to achieve benefits which comes from decreasing of uncertainty and improvement of managerial decisions. There six categories of business values potentially affected in this positive way are as follows [14]:

1. Quality. In addition to the general improvement in quality, there are possible benefits of prediction (based on Big Data analysis) of quality issues.

2. Warranty cost and service. Better service that comes from a better awareness of product configuration. Proactive and more accurate definition of warranty and claims issues based on the equilibrium of warranty costs and customer experience.

3. Operation costs. Better critical performance from Lean Manufacturing implemented on more accurate data including those obtained through prediction. Improved new product development processes.

4. Record retention and serialisation. Better trackability of entities of goods through the logistics cycle of the product; from material procurement, through manufacturing to distribution.

5. New product introduction cost and lead time.

6. Revenue growth opportunities. New business opportunities based on the better identification of potential customer readiness to upgrade product in the field. Improved efficiency and cost of service.

\section{Prototyping digital twins with FlexSim}

\subsection{The FlexSim software features}

FlexSim Simulation Software package enables modelling of real-life systems and discrete-time simulation with visualisation in 3D technology, including virtual reality experience. Fig.4. Illustrates essential components which are common for such a class of software.

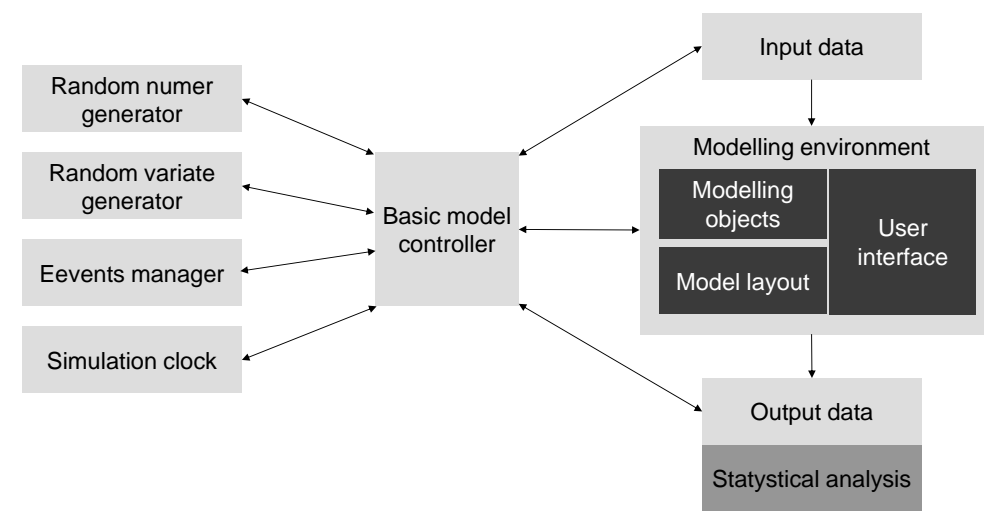

Fig. 4. Components of simulation software. Adopted from [15]. 
Since its appearance in the market (2003), FlexSim has earned popularity among engineers, designers and analysts matching their requirements in making decisions in the field of process design and operation. With FlexSim's realistic graphical 3D animation and extensive performance reports (customised dashboards), a user with a series of simulations can track problems and evaluate alternative solutions in a relatively short amount of time.

There are generally three ways to employ optimisation methods for simulation modelling in FlexSim:

1) using Simulation Experimenter Control tool with build-in OptQuest (requires an additional licence) that solves problems with evolutionary algorithms,

2) using Flexiscript (internal script language) to batch processing and exchange of data with third-party software;

3) using FlexSim's ability to link to external DLLs (dynamic-link libraries).

Those features give the possibilities to combine FlexSim and Scilab or Matlab, to handle Linear Programming optimisation and simulation analysis.

In 2017 new features has been introduced to improve interconnections of virtual models with the physical world: The Emulation tool to control 3D models with simulated programmable logic controllers (PLC) logic. This tool is for developing and testing the PLC logic within a simulation model of the whole automation system. The emulation tool works in two different modes due to connections between the model and the physical world (Fig.5):

1) Inactive connection mode - all Sensors and Controls PLC data are exchanged with the simulation model during simulation,

2) Active connection mode - all Sensors and Controls PLC data are exchanged with OPC server or directly with PLC through serial communication protocol Modbus.

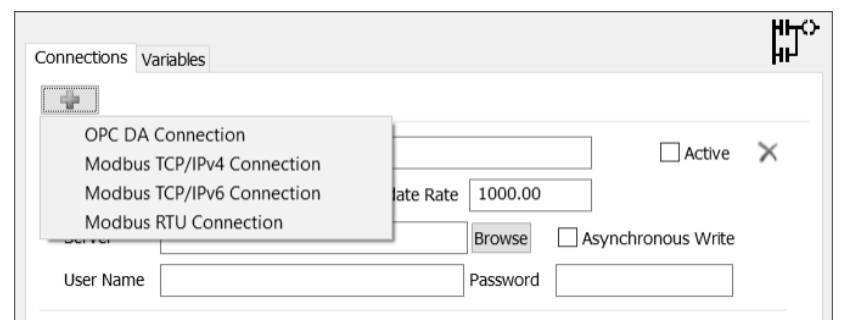

Fig. 5. Connectivity options for Emulation tool in FlexSim.

Open Platform Communications OPC is the interoperability standard for exchange of data in the industrial automation. Figure 6 outlines the basic configuration with OPC Classical connections.

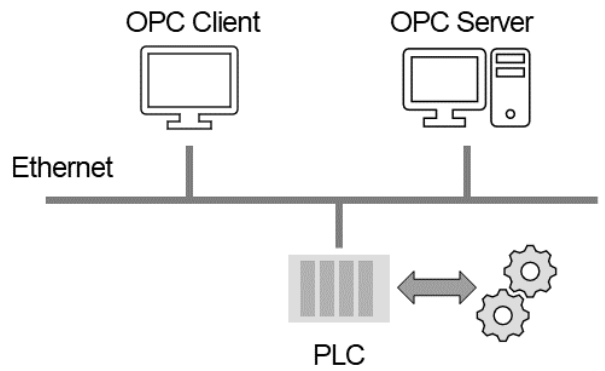

Fig. 6. OPC Classical connection for a pair of OPC client/ PLC. 
The OPC Classic is based on Microsoft Windows technology (Distributed Component Object Model) for the exchange of data between software components. The OPC DA uses client/server technology; specification of the standard defines the exchange of data including values, time and quality information [16].

Figure 7. presents layout (screenshot in VR mode) of simple automation solution for conveyor supplying CNC machine.

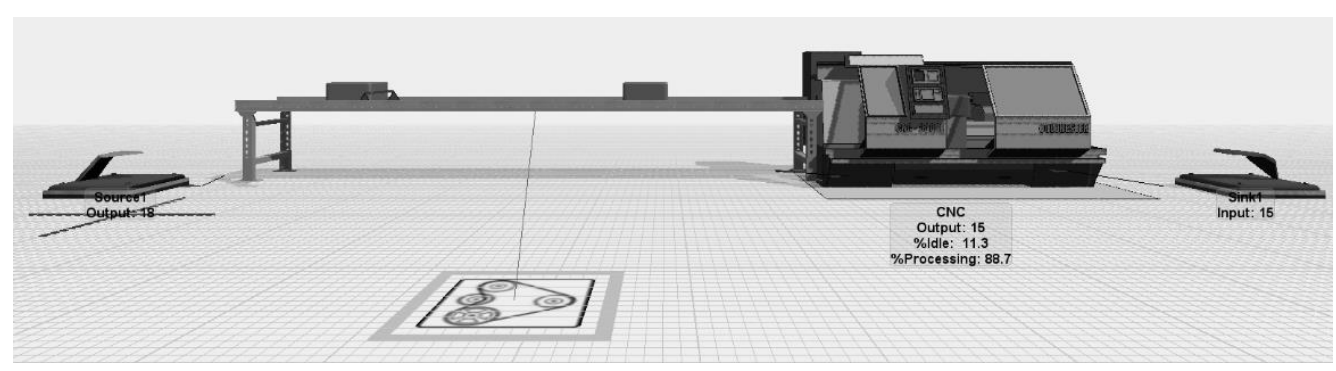

Fig. 7. Simple automated production line.

Each time when box passes Photo Eye Sensor placed on the conveyor, the the motor drive stops for 6 seconds and starts again. Figure 8. presents a screenshot of PLC logic for the above model.

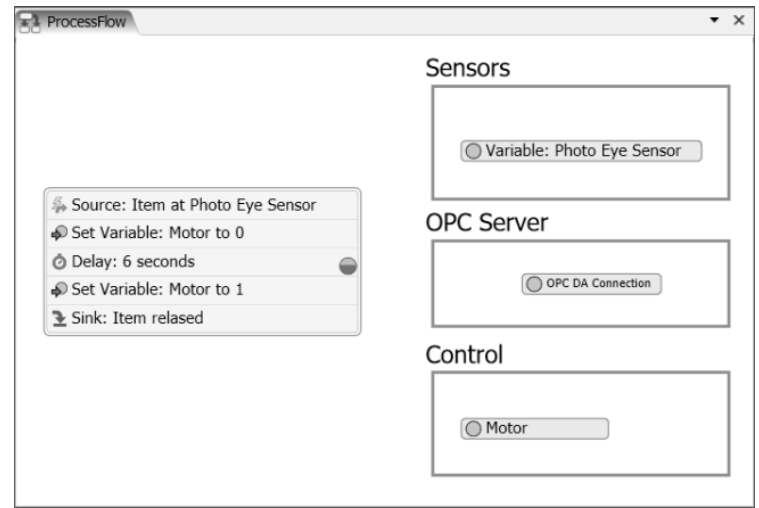

Fig. 9. PLC logic editor screenshot.

\subsection{Prototyping Digital Twins}

PLC Emulation and connectivity of simulation models combined with optimisation features and SQL databases access makes FlexSim promising choice for prototyping and experimenting with digital twin concept. Fig. 10. illustrates the configuration of digital twining with FlexSim about the concept of Digital Twin Shop-floor (see Fig.3.). The FlexSim software provides limited functionality in realtion to full specification of Shop-floor Service System but still can supply a significant amount of data for analysing and identifying possible issues in modelled processes. The powerful 3D simulation environment with optimisation features make the process of modelling and simulation attractive and practical. There is a wide 
variety of OPC software to chose from and it is realitivly easy set up a server, even on the same PC that hosts FlexSim.

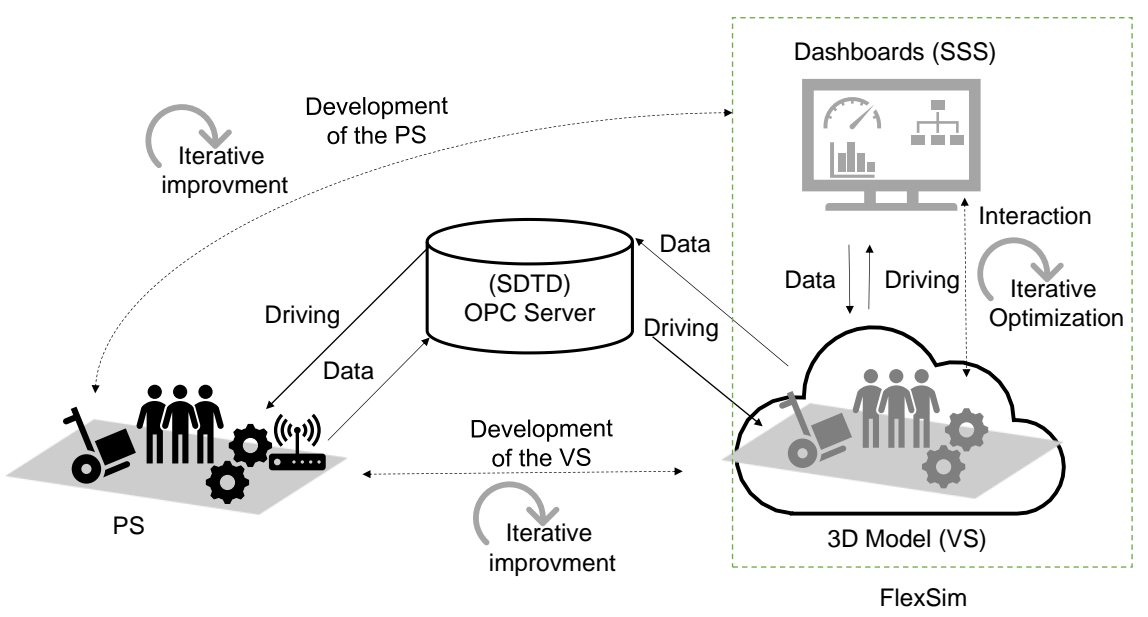

Fig. 10. Digital twining with FlexSim.

The process of prototyping and research on the Digital Twins by applying software products which support open standards in communication and control is essential for the usability of developed solutions.

\section{Conclusions}

The Smart Industry is the hottest idea discussed and developed both by practiotioners and academia. The concpet of digitalisation shop-floor through applying digital twins systems makes this vision much clear and recognisable. It is a time to reaserch possibilites of rapid prototyping for digital twining with applying advanced simulation technologies which are already aviable. Flexsim is the one of promient sofware packages like Simio, Any Logic an the others.

\section{References}

[1] Prifti, L., et al. A Competency Model for "Industrie 4.0" Employees. [ed.] J.M. Leimeister and W. Brenner. Proceedings der 13. Internationalen Tagung Wirtschaftsinformatik (WI 2017). St. Gallen : s.n., 2017, pp. 46-60.

[2] Tao, F., Cheng, J and Qi, Q. Digital twin-driven product design, manufacturing and service with big data. International Journal of Advanced Manufacturing Technology. February 2018, Vol. 94, Issue 9-12, pp. 3563-3576.

[3] Guinard, D. and Trifa, V. Building the Web of Things. s.1. : Manning Publications Co., 2016. 
[4] Lee, E. Cyber Physical Systems: Design Challenges. 2008 11th IEEE International Symposium on Object and Component-Oriented Real-Time Distributed Computing (ISORC). Orlando, FL, USA : IEEE, 2008, pp. 363-369.

[5] Rondeau, P.J. and Litteral, L.A. The evolution of manufacturing planning and control systems: From reorder point to enterprise resource planning. Production and Inventory Management Journal. 2001, Vol. Vol. 34, No. 2, pp. pp. 1-7.

[6] Luściński, S. Perspectives On Data Engineering: Emerging Role In Organisation Development. [ed.] R. Knosala. Innowacje w zarządzaniu i inżynierii produkcji. Opole : Oficyna Wydawnicza Polskiego Towarzystwa Zarządzania Produkcją, 2015, Vol. II, pp. 767-779.

[7] Lee, J, Bagheri, B. and Kao, H. A Cyber-Physical Systems architecture for Industry 4.0based manufacturing systems. Manufacturing Letters. January 2015, Vol. 3, pp. 18-23.

[8] Panetta, K. Gartner's Top 10 Strategic Technology Trends for 2017. Technology Trends Smarter With Gartner. [Online] Gartner, Inc., 18 Oct. 2016. [Cited: 15 Aug. 2018.]

https://www.gartner.com/smarterwithgartner/gartners-top-10-technology-trends-2017/.

[9] Pettey, C. Prepare for the Impact of Digital Twins. Technology Trends - Smarter With Gartner. [Online] Gartner, Inc., 18 Sept. 2017. [Cited: 15 May 2018.]

https://www.gartner.com/smarterwithgartner/prepare-for-the-impact-of-digital-twins/.

[10] Goering, R. EDA in the 1980s - the "Dazzling Decade" of Electronic Design Automation.

Cadence Community. [Online] 1 Aug 2013. [Cited: 15 Aug 2018.]

https://community.cadence.com/cadence_blogs_8/b/ii/posts/eda-in-the-1980s-the-dazzling-decadeof-electronic-design-automation.

[11] Tao, F. and Zhang, M. Digital Twin Shop-Floor: A New Shop-Floor Paradigm Towards Smart Manufacturing. IEEE Access. IEEE, 26 Sept. 2017, Vol. 5, pp. 20418-20427.

[12] Manyika, J., et al. Big data: The next frontier for innovation, competition, and productivity. McKinsey\&Company Home Page. [Online] June 2011. [Cited: 1 Dec 2014.]

http://www.mckinsey.com/insights/business_technology/big_data_the_next_frontier_for_innovatio n.

[13] Zhuang, C., Liu, J and Xiong, H. Digital twin-based smart production management and control framework for the complex product assembly shop-floor. The International Journal of Advanced Manufacturing Technology. April, 2018, Vol. 96, Issue 1-4, pp. 1149-1163.

[14] Parrott, A. and Warshaw, L. Industry 4.0 and the digital twin. Manufacturing meets its match. [Online] 2017. https://www2.deloitte.com/content/dam/Deloitte/cn/Documents/cip/deloittecn-cip-industry-4-0-digital-twin-technology-en-171215.pdf.

[15] Beaverstocks M, Greenwood A., Lavery E., Nordgen W. AppliedSimulation. Modelling and Analysis using FlexSim. 4th. Orem: FlexSim Software Products, Inc., 2014.

[16] OPC Foundation. Home Page - OPC Foundation. [Online] 2018. [Cited: 22 Aug. 2018.] https://opcfoundation.org/. 